\title{
CUADERNO DE PEDAGOGIA UNIVERSITARIA
}

Publicación Semestral

Año 12. Número 24 / julio - diciembre 2015 / ISSN 18144144

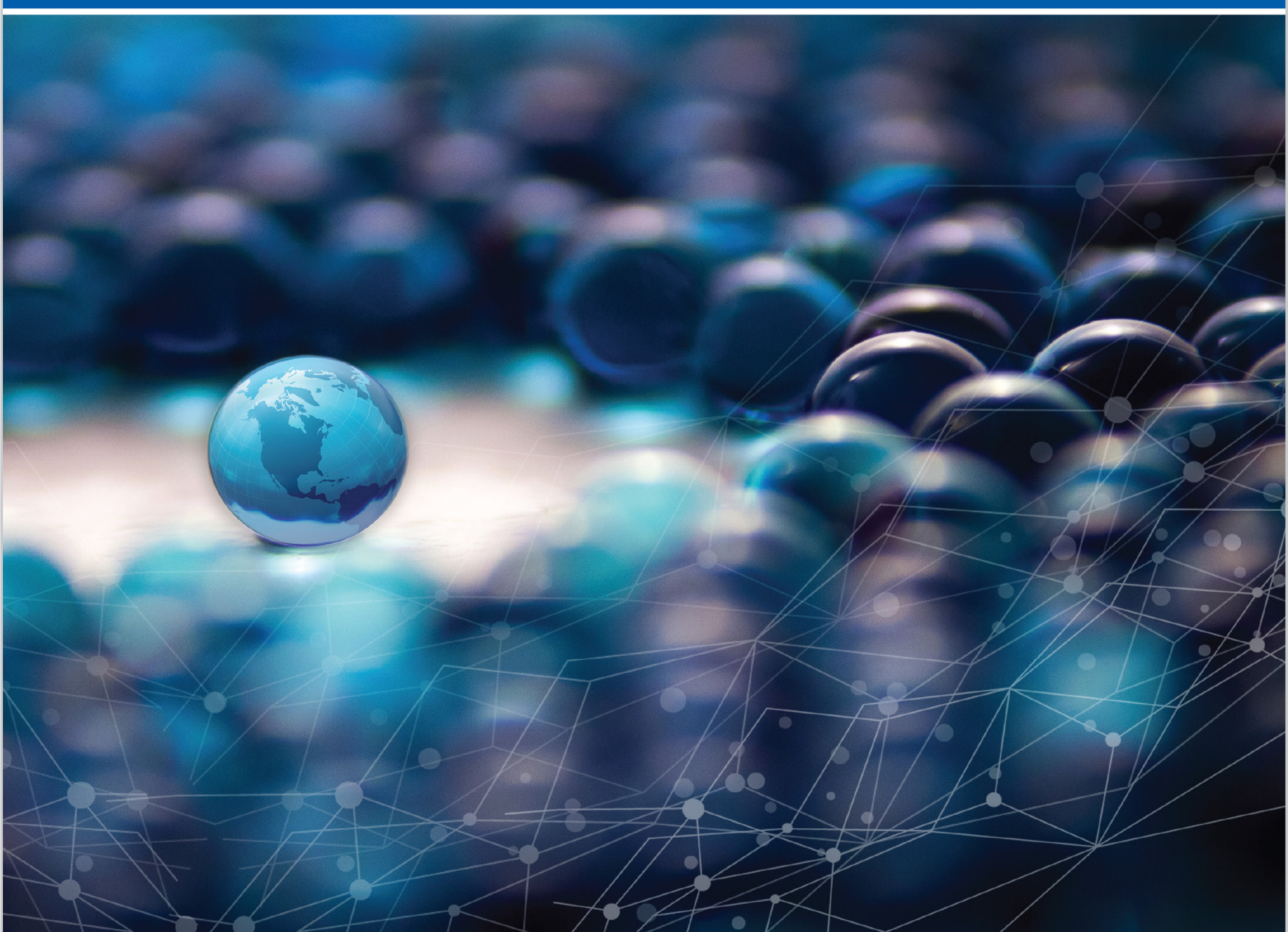

En esta sección compartimos las opiniones que nos envían nuestros lectores sobre los artículos publicados en el último ejemplar del Cuaderno de Pedagogía Universitaria: No. 24 / julio - diciembre 2015

\section{Competencias comunicativas y su incidencia en el desarrollo de los procesos de comprensión y producción discursiva-académica}

Muy interesante el artículo "Competencias comunicativas y su incidencia en el desarrollo de los procesos de comprensión y producción discursiva-académica” del profesor José Alejandro Rodríguez Núñez. Explica muy bien la importancia de desarrollar en los estudiantes estas competencias comunicativas, partiendo de que son la base fundamental del desarrollo humano y la interacción social. Provee herramientas para desarrollar estas destrezas 
comunicativas que mejoren las habilidades dialógicas entre los actores del acto comunicativo.

El artículo me hace reflexionar sobre cómo seguir optimizando la planificación de las asignaturas que imparto, adoptando un giro más comunicativoparticipativo, el cual desarrolle profesionales capaces de recibir y transmitir el conocimiento de una manera más efectiva, logrando así ser exitosos en este competitivo mundo de hoy.

Prof. Nurys Karina García Departamento de Administración de Empresas Campus de Santiago

\section{El resumen como estrategia para mejorar la comprensión lectora en la asignatura Derecho de los Contratos}

Este artículo, fruto de la investigación-acción, de la profesora Sahyly Wehbe, me resultó particularmente interesante por dos razones. La primera de ellas es el enfoque del resumen como estrategia cognitiva: la comprensión de la lectura. Resumir para aprender y para aprehender. Así, el estudiante es el protagonista de su aprendizaje. La segunda, corresponde al aspecto pedagógico-metodológico de construcción del conocimiento: el resumen como proceso y no como producto. Entiendo que todos los docentes podemos implementar lo propuesto por la abogada en cualquier asignatura. Mis felicitaciones y mi compromiso de emularla.

Prof. Edwin Paniagua Departamento de Español Campus de Santiago

Factores que determinan el sentido de pertenencia de los estudiantes de la PUCMMCSTA

El sentido de pertenencia a una institución favorece la correcta ejecución de distintos procesos, incluyendo el de enseñanza-aprendizaje. Esta es una de las informaciones que podemos derivar de la investigación "Factores que determinan el sentido de pertenencia de los estudiantes de la PUCMM-CSTA". Los datos que nos ofrece la profesora Brea deben calar profundamente en nuestra conciencia y en nuestra práctica docente, de tal manera que gradualmente nos permitan reconocer y mejorar el propio sentido de apego que tenemos los docentes con la Universidad. Luego, podremos transmitirlo a los estudiantes a través del afecto y empeño con los que realicemos cada proyecto y con los que tratemos a cada uno de estos profesionales en formación.

Percibo que el valor de esta investigación es incalculable y que el adecuado uso de estos resultados permitiría en cierto modo una mejora en el desempeño docente y estudiantil en la Universidad. Su utilización podría, incluso, tener un efecto sinérgico con otros proyectos institucionales, como es el caso del Plan Estratégico 2016-2021. Felicidades a la autora por estos logros, pues quizás sin proponérselo ha obtenido unos datos útiles en más de un aspecto. ¡Enhorabuena!

\section{Dr. Luis Ronald Capellán Céspedes Profesor del Departamento de Medicina Campus de Santiago}

Esta investigación sobre los factores que inciden en la identificación de los alumnos con la Universidad es de alta importancia y enriquecedora perspectiva. Sin embargo, quisiera agregar algo sobre la identificación con la Universidad que se remonta un poco antes del examen de admisión. Es recomendable que el solicitante de nuevo ingreso conozca bien el lugar donde va a convivir durante los próximos años de su vida.

Esto asegura que interiorice los reglamentos y estatutos de la Pontificia Universidad Católica Madre y Maestra, así también debe escuchar las percepciones de exalumnos y futuros estudiantes. El acercamiento a este contexto facilitará la comprensión sobre el ambiente cultural donde va a participar el estudiante durante su vida académica.

Puedo notar por mi experiencia que aquellos estudiantes y padres que han aceptado que, para integrarse, primero hay que contextualizarse, entonces ocurren experiencias académicas que marcan e inspiran. ¿De qué otra manera sería posible pertenecer si no se cuenta con la magnífica y maravillosa diversidad que compone esta Universidad?

Raúl Yunén

Departamento de Comunicación Social Campus de Santiago 